\title{
Ameliorative Effects of Pomegranate Peel Extract on Hepatotoxicity Induced by Carbon Tetrachloride in Mice
}

\author{
${ }^{1}$ Mona Abdel Rahman Ibrahim, ${ }^{2}$ Hanan Ali Mahmoud Okail, \\ ${ }^{3}$ Nahed Mohamed Mansour Emam
}

${ }^{1}$ Department of zoology, Faculty of Science, Helwan University,Egypt, ${ }^{2}$ Department of zoology, Faculty of Science, Sohag University, Egypt, ${ }^{3}$ Department of zoology, Faculty of Science, Al-Arish University, Egypt.

\begin{abstract}
Pomegranate peel extracts (PPE) have been shown to possess significant antioxidant activity. This study aimed to evaluate the protective effect of PPE on carbon tetrachloride (CCl4)-induced toxicity in mice. Forty adult mice were divided into four groups of 10 mice each. The first group was kept as a control. The second group was administered orally by PPE $(400 \mathrm{mg} / \mathrm{kg})$ for 15 days. The third group was intraperitoneally injected by a mixture of $(1 \mathrm{ml} / \mathrm{kg})$ of CCl4 and sterile olive oil [1:1(v/v)] two times a week for 15 days. The fourth Group was injected (IP) by a mixture of $(1 \mathrm{ml} / \mathrm{kg})$ of CCl4 and sterile olive oil [1:1(v/v)] two times a week concurrently with a daily oral dose of PPE $(400 \mathrm{mg} / \mathrm{kg})$ for 15 days. The biochemical studies showed that CCl4intoxication induced a significant increase in serum of aspartate amino transferase (AST) and alanine amino transferase (ALT) levels and treatment with PPE showed decreased in these elevated enzymes. The histological examination of liver sections treated with CCl4 showed vacuolization, deterioration of the cytoplasm, necrosis, fatty degeneration and interstitial fibrosis which were improved by PPE treatment. By using Mallory's trichrome technique, CCl4-treated group illustrated highly increase of the collagen fibers and PPE treatment caused a detectable decrease of the collagen fibers. Also, CCl4-treated mice showed a significant increase in caspase-3 production which decrease by the treatment with PPE.
\end{abstract}

In conclusion, our results demonstrated that PPE through its antioxidant action efficiently improve the liver toxicity induced by CCl4.

Keywords: Punica -granatum - CCl4- histopathology - liver -enzymes

\section{INTRODUCTION}

Various pharmaceutical substances and chemicals may induce diverse levels of hepatopathy, from asymptomatic hepatic lesions to extensive liver necrosis. Carbon tetrachloride $\left(\mathrm{CCl}_{4}\right)$, is well known hepato-destructive agent that is widely used to induce toxic liver damage in a range of laboratory animals [1] .The toxic effects in liver such as fatty degeneration, centrilobular necrosis followed by hepatic fibrosis, hepatocellular apoptosis and carcinogenicity have been associated with $\mathrm{CCl}_{4}$ toxicity [2].

Foods rich in natural antioxidants have been proposed as an tool to prevent and cure liver damage [3]. Punica granatum (PG), commonly known as pomegranate, is a shrub or a small tree, native to the Mediterranean area. A number of biological activities have been reported on various extracts/constituents of different parts of this plant such as, antibacterial [4] antifungal [5], antiulcer [6] and antitumour [7]. Recently, the antioxidant activity of pomegranate is obvious among in pomegranate fruit, juice and peel [8], this is due to that Pomegranate contains large amounts of polyphenols and flavonoid [9].

Pomegranate peel extracts (PPE) with large quantity of flavonoids and tannins have been shown a high antioxidant activity in several studies [10]. In addition Pomegranate peel is branded for its many health promoting qualities and apparent wound-healing properties [11] anticancer property [7, 12], antiatherosclerotic and antioxidative capacities [13]. Furthermore, recent many studies have proved the hepatoprotective property of pomegranate that possesses certain hepato-protective properties that making it an significant therapeutic agent in the treatment of hepatic fibrosis and oxidative damage [14]. [15]demonstrated the antioxidant activity of PPE accompanied with radio-protective and antifibrotic properties. Moreover,[16, 17] mentioned the protective role of pomegranate on fatty liver in 
obesity through improvement of abnormal lipid metabolism. Previous studies have demonstrated that PPE prevent CCl4 toxicity, particularly hepatotoxicity, by enhancing both alanine aminotransferase (ALT) and aspartate aminotransferase (AST) activities [18, 19], inhibition of collagen synthesis [20], increasing antioxidant enzyme activity and inhibiting lipid peroxidation [21].

The objective of the present study was to assess the protective effects of pomegranate peel extract against the toxic effects of carbon tetrachloride (CCl4) in liver of mice.

\section{Materials AND Methods}

\subsection{Preparation of the Plant Extract}

An aqueous extract of the P. granatum peel was used in this experiment. The extract was produced from the dry peel of pomegranate that purchased from a commercial market, Hail, Saudi Arabia. The peels were washed with water, dried, fragmented, and then grinded to produce powder. One liter of warm boiling water (100c degree) was added to $1 \mathrm{~kg}$ of peel powder and kept in closed container in the laboratory for 6 hours. The solvent was filtered and concerted on water bath to produce $100 \mathrm{mg}$ peel extract from $1 \mathrm{~kg}$ of dry peel. The herb/extract ratio was then 10/1. The PPE solution $10 \%$ was produced, finally, each $8 \mathrm{cc}$ of the water extract contained $6 \mathrm{~g}$ of the dry peel [22].

\subsection{Experiment Design}

The present experimental study was applied on cd-1 mice, among an average body weight of 20 to 30 grams obtained from the breeding unit of King Saud University, Rhyaid, KSA. Female mice were housed in wire cages and kept under conditions of regular light/dark cycles. The animals were fed on cubes containing crude protein, minerals and fibers. Vitamins were added as bright vegetables and the mice were provided with milk and tap water adlibitum.

The animals were divided into four groups; the first group is the control group (GI). The second group (GII) was given a daily oral dose of peel extract only $(400 \mathrm{mg} / \mathrm{kg}$ ) for 15 days. The third group (GIII) the animals received a mixture of $1 \mathrm{ml} / \mathrm{kg}$ of CCl4 (Merck, Germany) and sterile olive oil [1:1(v/v)] two times a week for 15 days intraperitoneally (IP). The fourth group (GIV) the animals received a mixture of $1 \mathrm{ml} / \mathrm{kg}$. of CCl4 (Merck, Germany) and sterile olive oil [1:1(v/v)] two times a week intraperitoneally (IP) with a daily oral dose of peel extract only $(400 \mathrm{mg} / \mathrm{kg}$ ) for 15 days [23].

\subsection{Blood Sample Collection}

The mice were anesthetized by means of chloroform at the end of the experiment and blood was drawn from the heart and collected in vacuum tube clot activator. Then the blood samples were centrifuged at $3500 \mathrm{rpm}$ for $10 \mathrm{~min}$ in a centrifuge to separate the serum. The both levels of Aspartate aminotransferase (AST) and Alanine amino transferase enzymes (ALT) were measured using commercial kits from Reflotron and Liquicolor Analyticals. All assessment assays and kits were performed in conformity with manufacturers' instructions and protocols.

\subsection{Histological Examination}

The mice liver tissues of both control and experimental groups were fixed in $10 \%$ formalin for $48 \mathrm{hr}$, after which they were kept in $70 \%$ alcohol. Then the specimens were dehydrated by ascending series of alcohol, one hour each, cleared in terpineol for 3 days and embedded in 3 changes of pure paraffin wax, one hour each. Sections, 5 microns thick, were cut and mounted on clean glass slides. The paraffin sections were stained with Harris's hematoxylin and eosin, cleared in xylol and mounted [24]. Sections of liver of the different groups were carefully examined and photomicrographs were made as requested.

\subsection{Mallory Triple Stain for Fibers}

Mallory's trichrome stain for demonstrating collagen fibers [25].

\subsection{Immunohistochemistry Examination}

Immunohistochemical staining of anti-caspase-3 antibody was performed by streptoavidin-biotin. The liver sections of $4 \mu \mathrm{m}$ in thickness were deparaffinized and incubated with fresh $0.3 \%$ hydrogen peroxide in the methanol for 30 minutes at room temperature. The hepatic specimens were incubated with anti-caspase-3 antibody as primer antibody at 1/100 dilutions. Then, the specimens were counterstained with hematoxylin and eosin stains. The Negative controls were prepared by substituting normal mice serum for each primary antibody [26]. 

Mice

\subsection{Statistical Analysis}

The values were articulated as mean \pm SEM. Moreover, the statistical analyses were performed by the one way analysis of variance (ANOVA), (P values) $\leq 0.05$ were measured as significant values.

\section{RESUTLS}

\subsection{Biochemical Analysis}

Table- 1 shows serum activities of AST and ALT levels of mice in control, PPE, $\mathrm{CCl}_{4}$ and $\mathrm{CCl}_{4}+$ PPE groups. Significant increases $(P<0.05)$ were recorded in serum activities of AST and ALT levels due to the administration of $\mathrm{CCl}_{4}$ by 7.15 fold and 5 folds respectively as compared to the control group. However, the concomitant administration of PPE $(400 \mathrm{mg} / \mathrm{kg})$ with $\mathrm{CCl}_{4}(1 \mathrm{mg} / \mathrm{kg})$ alleviated the elevated levels of serum activities of AST and ALT induced by $\mathrm{CCl}_{4}$ significantly. In the group (IV), the inhibitory effects of pomegranate peel aqueous extract have a highly potent effect on the serum activities of AST and ALT levels compared to $\mathrm{CCl}_{4}$-treated group and restored AST and ALT levels to nearly normal as compared to mice in the control group. On the other hand, the PPE-treated group did not illustrate any significant $(\mathrm{p}>0.05)$ change in the levels of serum activities of AST and ALT compared to control.

Table1. Effects of Pomegranate peel extract (PPE) and /or $\mathrm{CCl}_{4}$ administration on Serum activities of AST and ALT levels in mice.

\begin{tabular}{|c|c|c|c|c|}
\hline Parameters & GI (Control) & GII (PPE) & GIII $\left(\mathrm{CCl}_{4}\right)$ & GIV $\left(\mathrm{CCl}_{4}+\right.$ PPE) \\
\hline AST (U/L) & $140 \pm 22.14$ & $155 \pm 32.14$ & $1141 \pm 56.34^{*}$ & $310 \pm 46.8^{*}$ \\
\%change & & $10.7 \%$ & $715 \%$ & $121 \%$ \\
\hline ALT (U/L) & $31 \pm 6.6$ & $26.33 \pm 3.6$ & $210 \pm 20.3 *$ & $71 \pm 9.7^{*}$ \\
\%change & & $-24.2 \%$ & $500 \%$ & $102 \%$ \\
\hline
\end{tabular}

Data are presented as mean $( \pm S D)$. *Significantly different from the control group $(P<0.05)$. \%change to con: $\%$ change to control level

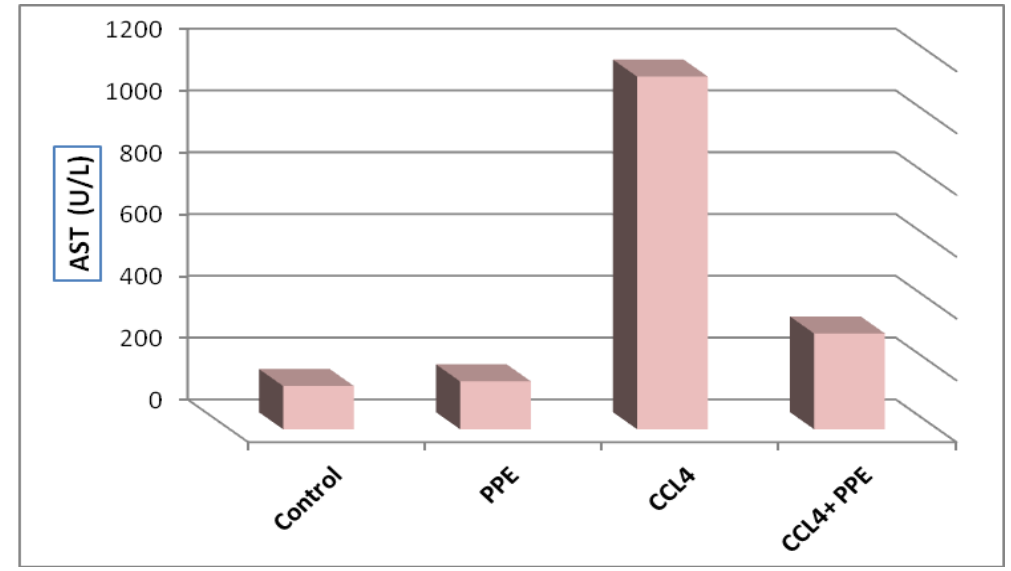

Figure1. Effects of Pomegranate peel extract (PPE) and /or $\mathrm{CCl}_{4}$ administration on AST activity in mice serum

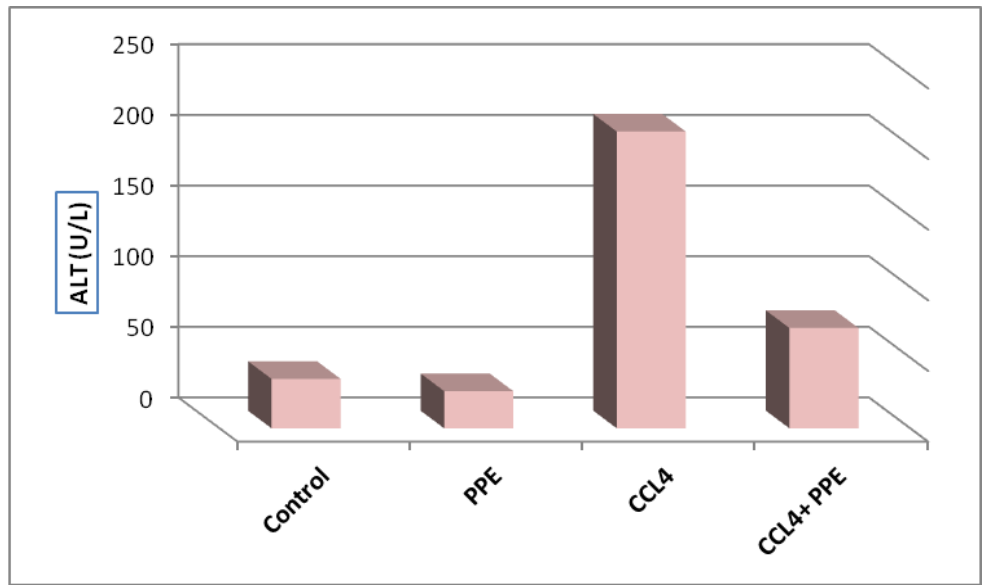

Figure2. Effects of Pomegranate peel extract (PPE) and /or $\mathrm{CCl}_{4}$ on ALT activity in mice serum 


\subsection{Histological Results}

Liver sections from the control group showed a normal histological appearance (Fig. 3a) in which, regular morphology of liver lobules with well designated hepatic cells and hepatic sinusoids. Also, liver sections obtained from mice treated with PPE alone showed more or less normal appearance with some cellular swelling, cytoplasmic vacuolization and granulation. The nuclei appeared mostly normal (Fig.3b). However, liver sections of mice treated with $\mathrm{CCl}_{4}$ demonstrated disrupted hepatic lobule structure, fatty degeneration, diffuse ballooning and lipid degeneration, severe necrosis, loosening of hepatic cells and large number of inflammatory cells infiltrated into necrotic lesion area (Fig.3c). The treatment of $\mathrm{CCl}_{4}$ - treated group with PPE showed somewhat reversed the hepatic lesions induced by $\mathrm{CCl}_{4}$ alone. The liver tissue appeared in an intact architecture with some normal nuclei and less ballooning, degenerated areas and fatty degeneration than those observed in $\mathrm{CCl}_{4}$ treated group. But the pale stained hepatocytes with vacuolization, necrotic cells and numbers of inflammatory cells infiltration were still observed (Fig.3d).

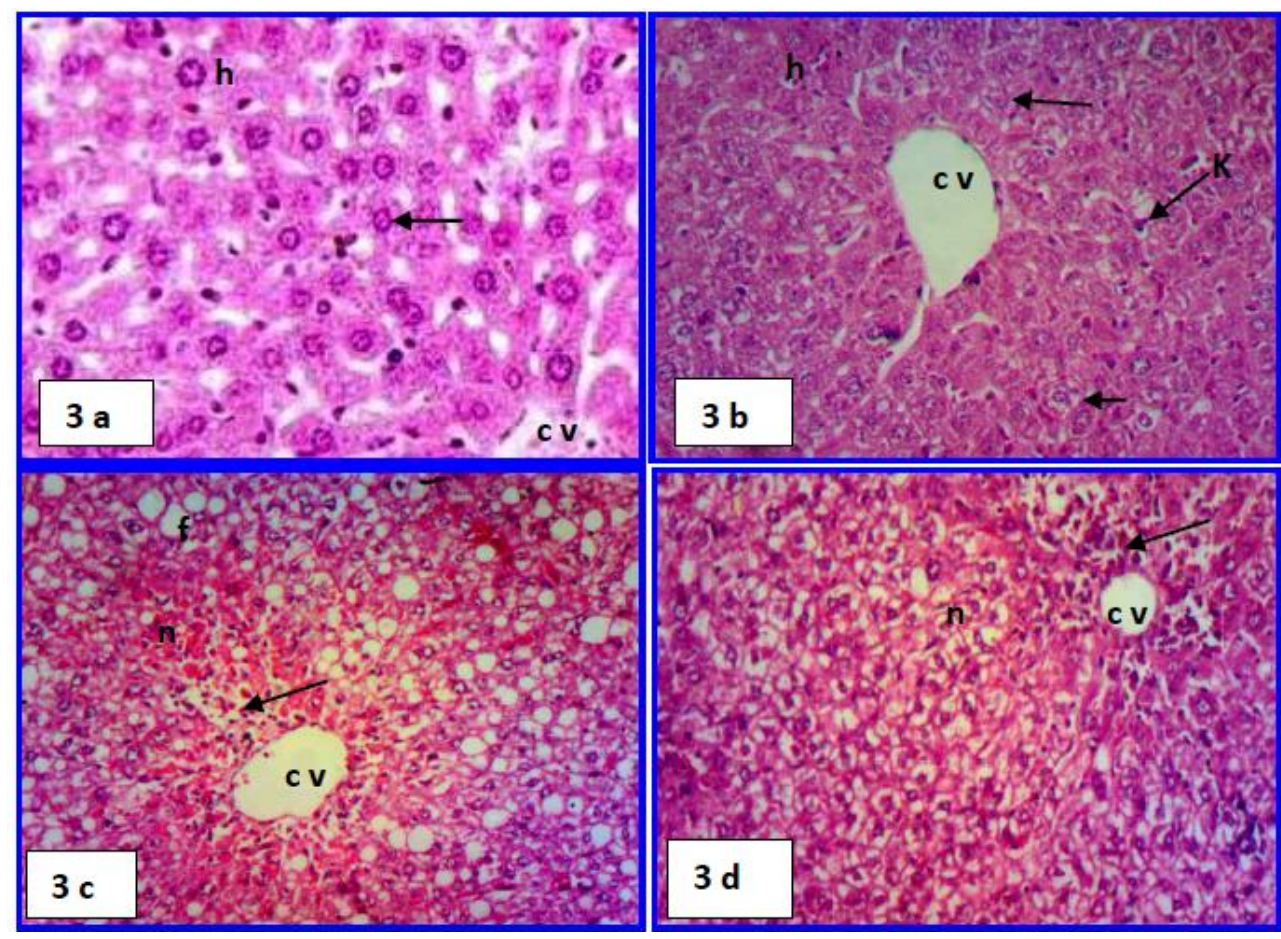

Figure3. Photomicrographs from liver tissues collected from mice of control, $P P E, C C l_{4}$, and $P P E+C C l_{4}$ groups stained with hematoxylin-eosin. Fig. (3a): For the control group showing, normal histological structure of the central vein (cv) and surrounding hepatocytes (h) with normal nuclei (arrow) (40X). Fig. (3b): liver tissue of PPE- treated group showed some cellular swelling with cytoplasmic vacuolization ( short arrow) and granulation, with mostly normal nuclei (long arrow) and Van-Kupffer cells (k). Fig.(3c): liver tissue of $\mathrm{CCl}_{4}$-treated group showed pale stained hepatocytes, massive fatty degeneration ( $f$ ), necrotic hepatocytes $(n)$ with severe ballooning degeneration and massive number of inflammatory cells infiltration into lesion area (arrow) (40X). Fig.(3d): liver tissue of a mouse with PPE+CCl ${ }_{4}$ treatments resulted in less fatty changes, necrosis and ballooning degeneration areas than those observed to $\mathrm{CCl}_{4}$ alone. However, pale stained hepatocytes with cytoplasmic vacuolization, necrotic cells $(n)$ and numbers of inflammatory cells infiltration (arrow) were still detected (40X).

\section{Mallory's Trichrome-Stained Tissues}

The alternations induced in the connective tissue especially within the collagen fibers in liver tissues in both control and treated groups were investigated by Mallory's trichrome technique (Fig. 2). Hepatic tissues of control sections revealed blue stained collagen fibers within the portal areas, around the central veins and scattered fibers at the lining of the hepatic sinusoids (Fig.4a). The collagen fibers in liver tissues of mice treated with PPE were more or less similar to those of the control sections (Fig.4b). The portal areas of $\mathrm{CCl}_{4^{-}}$treated group indicated highly increase of the collagen fibers noticed around branches of the portal veins which exhibited a very thick lining epithelium and scattered fibers were observed at the lining of the hepatic sinusoids (Fig. 4c). Also numerous hemorrhagic areas were observed. Figure (4d) showing decreased in the collagen fibers content of both peel plus CCl4 treated mice as compared to those observed in CCl4 alone. 


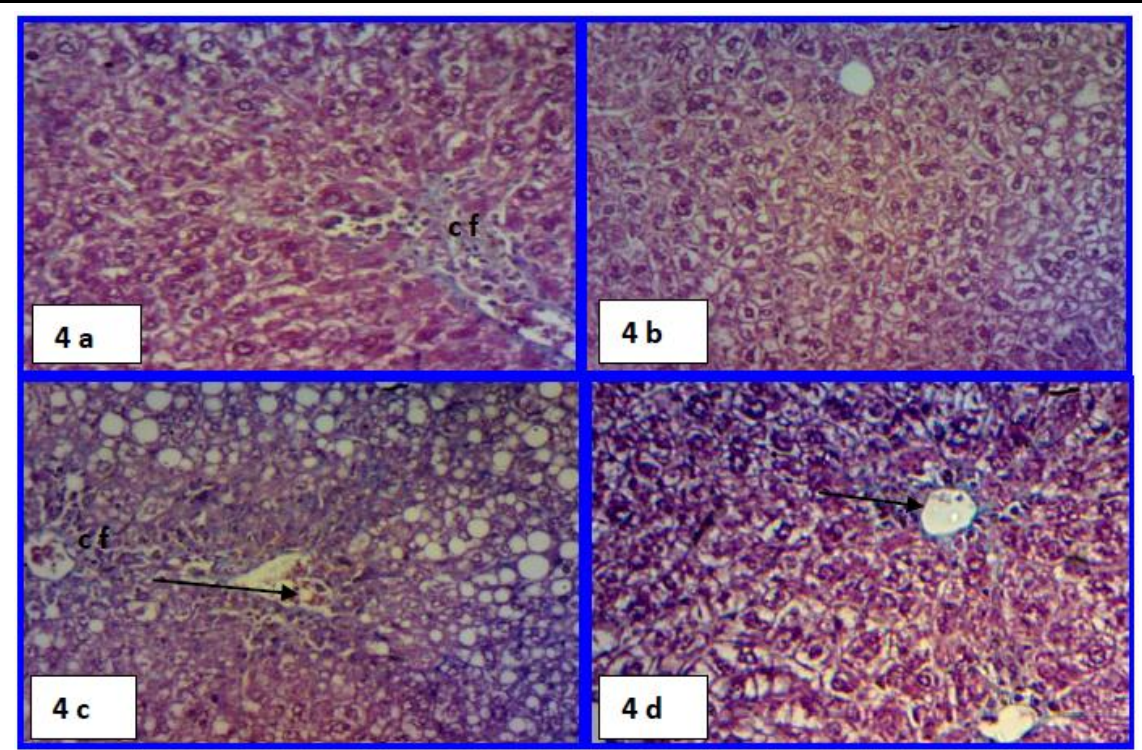

Figure4. Photomicrographs from liver tissues collected from mice of control, $P P E, C C l_{4}$, and $P P E+C C l_{4}$ groups stained with Mallory's Trichorome Stain. Fig. (4a): control group showing blue stained collagen fibers (cf) arranged in between branches of the hepatic portal vein (40X). Fig.(4b): PPE-treated group showing, nearly normal blue stained collagen fibers content in the tissue (40X). Fig. (4c): $C C l_{4} \cdot$ treated mice showed extensive increased collagenous bundles throughout the tissue (cf). Also numerous hemorrhagic areas could be detected (arrow) (40X). Fig. (4d): $\mathrm{PPE}+\mathrm{CCl}_{4}$ group showing some collagenous fibers surrounding the central vein (arrow) of peel plus $\mathrm{CCl}_{4}$. treated mice $(40 \mathrm{X})$.

\subsection{Immunohistochemical Results}

$\mathrm{CCl}_{4}$ treatment produced intensive increased in the amount of Caspase- 3 in mice (Fig.5c) indicated by the intensive brown stain as compared to normal control group (Fig. 5a). The administration of peel extract only showed also more or less normal appearance of Caspase-3 (Fig. 5b). The treatment of mice with peel extract plus $\mathrm{CCl}_{4}$ also exhibited slight decrease in the Caspase -3 amounts indicated by less intense brown color compared to those of $\mathrm{CCl} 4$ group only indicating incomplete heeling for $\mathrm{CCl}_{4}$ pathological effects by the used dose or duration of the peel extract (Fig.5d).
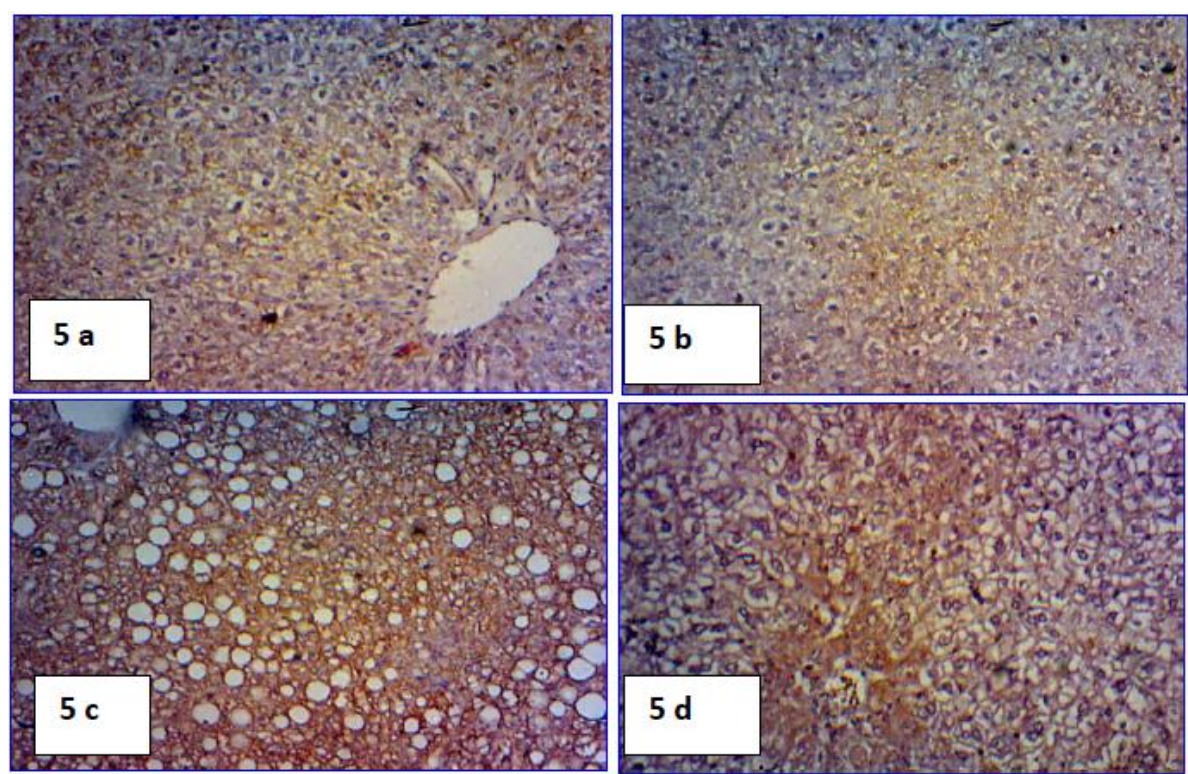

Figure5. Photomicrographs from liver tissues collected from mice of control, $P P E, C C l_{4}$, and $P P E+C C l_{4}$ groups stained with Caspase-3-immunostaining. Fig.(5b): Liver tissue of peel extract treated mouse showing positive immunoreactivity for caspase- 3 Indicated by faint brown staining in the hepatic tissue and around the central vein (40X). Fig. (5c): Liver tissue of $\mathrm{CCl}_{4}$ treated mouse showing intensive reaction for positive immunoreactivity for caspase-3.indicated by dense brown staining in the hepatic tissue and around the central vein (40X). Fig.(3d): Liver tissue of PPE plus $C_{C l}$ treated mouse showing marked decrease in caspase- 3 amount compared to $\mathrm{CCl}_{4}$ group alone $(40 \mathrm{X})$. 


\section{DISCUSSION}

$\mathrm{CCl}_{4}$ has been one of the most intensively studied hepatotoxicants and it consistently produces liver injury in many species [27]. Acute poisoning with $\mathrm{CCl}_{4}$ becomes manifested as a multisystem disorder, involving the liver, kidneys, brain, lungs, adrenal glands, and myocardium [28] .The present study demonstrates the ameliorated role of pomegranate peel aqueous extract against the effects carbon tetrachloride-induced hepatotoxicity.

In the present study, $\mathrm{CCl}_{4}$-treated group showed acute hepatotoxic effects of $\mathrm{CCl}_{4}$ as a significant increase in liver enzymes (AST and ALT) which confirmed by the histopathological results that showed considerable structural changes including, fatty degeneration, severely necrosis, cytoplasm loosening of hepatic cells and massive number of inflammatory cells infiltration. These results are in accordance with other findings showing that histopathological alternations in the liver tissue are accompanied with an increase in the levels of serum levels of AST and ALT [29, 30]. However, the elevated levels of serum marker enzymes may explain cell membrane break down and cell death [31].

The hepatotoxic effect of $\mathrm{CCl} 4$ detected in the present study might be due to oxidative stress of $\mathrm{CCl} 4$ which induces reactive oxygen species (ROS) and depletes antioxidant defenses, including antioxidant enzymes and their substrates causing oxidative stress in multiple tissues [32]. The same authors reported that the mechanism of $\mathrm{CCl}_{4}$ injury involves oxidative damage by metabolism of $\mathrm{CCl}_{4}$ to trichloromethyl radical $\left(\mathrm{CCl}_{3}\right)$ which is subsequently changed into more destructive trichloromethyl peroxy radical $\left(\mathrm{CCl}_{3} \mathrm{OO}\right)$ in hepatocytes. These radicals initiate lipid peroxidation chain reactions causing severe cellular damage, which induces the progress of fibrosis in the liver.

It was shown in this study that the significant elevation in serum ALT and AST activities were noted in mice treated with $\mathrm{CCl}_{4}$ were ameliorated by administration of the PPE. Also, the hepato protective effects of EPP were further evidenced by obvious improvement in histopathological examination. These findings are in agreement with those of $[19,33]$ who found that administration of pomegranate peel extract significantly reduced the damaging impact of $\mathrm{CCl}_{4}$ on the liver. These results provided evidence that the PPE is able to improve hepatic steatosis in mice without obvious hepatotoxicity. The effect of Punica granatum on liver enzymes could be attributed to the antioxidant activity of its active constituents. All of Pomegranate juice or peel or seeds have a powerful antioxidant activity due to their active compounds that are certain electron donors, which can react with the free radicals to change them to more stable products and terminate the radical chain reaction [19, 21, 34]. These results are probably attributed to its linolenic acid and phenolic compounds contained in this Pomegranate plant. EPP mainly have total phenolics, including mainly hydrolysable tannins (ellagitannins), such as oligomers and punicalagin/punicalin [35]. The same authors added that, the antioxidant activity of both linolenic acid and phenolics are mainly due to their redox characteristics, which allow them to do as reducing agents, metal chelators, hydrogen donors and singlet oxygen quenchers. Previous studies have demonstrated that Pomegranate Peel has anti-inflammatory, antioxidant, and anti-fibrotic activity [36, 37].

In the present study, $\mathrm{CCl}_{4^{-}}$treated group, investigated by Mallory's trichrome technique illustrated highly increase of the collagen fibers noticed around branches of the portal veins. Similar results were reported by many authors using $\mathrm{CCl}_{4}$ to induce liver fibrosis in animals. In this regard, [38] reported that liver fibrosis induced by $\mathrm{CCl}_{4}$ is associated with severe lipid peroxidation and antioxidants depletion which caused by damage in the cell membrane and organelles of hepatocytes. The $\mathrm{CCl}_{4}$ is metabolized by cytochrome $\mathrm{P} 450$ to format reactive trichloromethyl radical $\left(\mathrm{CCl}_{3}\right)$ and trichloromethyl peroxyl radical $(\mathrm{CCl} 3 \mathrm{O} 2)$. Both radicals have a good ability to binding to DNA, lipids, carbohydrates or proteins, causing lipid peroxidation, cell necrosis and severe deposition of collagen in liver and liver fibrosis [27]. Moreover, strong reactive oxygen species play a significant role in producing hepatic tissue destruction, amplifying the inflammatory response, motivating the production of profibrogenic mediators and so causing the hepatic fibrogenesis [39].

The treatment of female mice with $\mathrm{CCl}_{4}+\mathrm{PPE}$ caused a detectable decrease of the collagen fibers, these effects could be related to its antioxidant, antifibrotic and antiapoptotic properties [40]. Several lines of evidence have recently proved that oxidative stress plays vital role in liver fibrosis [41]. Antioxidants are effective for preventing liver fibrogenesis [42]. Moreover, EPP's antioxidant and antifibrotic properties may be the potent therapeutic value in protecting liver tissues from fibrosis and oxidative injury[35]. 
The Caspase-3, is the main executioner of programmed cell death concerned in cleavage of many apoptosis related proteins. The cleavage of many apoptosis related proteins by activated caspase- 3 provides one of the most utilize diagnostics for revealing of apoptosis in most cell type [43]. In the present study, $\mathrm{CCl}_{4}$-treated mice showed a significant increase in caspase-3 production which indicates severe apoptosis compared to the control group. These results are in accordance with other findings showing that $\mathrm{CCl}_{4}$ has been demonstrated to cause acute hepatotoxicity with apoptotic and necrotic hepatocellular injury and mutilation of liver function [44]. In addition, $\mathrm{CCl}_{4}$ is able to induce oxidative stress and apoptosis, cell cycle arrest as apoptosis (caspase 3) [45]. Moreover, $\mathrm{CCl}_{4^{-}}$ induced cell death involved caspase-3 activation [46]. On the other hand, the treatment of $\mathrm{CCl}_{4^{-}}$ treated mice with PPE showed decrease in caspase-3 production. These results suggest that Pomegranate Peel protects liver tissue against $\mathrm{CCl}_{4}$-induced oxidative stress by both increasing the anti-apoptotic protein production and decreasing the production of apoptotic proteins. In agreement with [38] pretreatment with Pomegranate Peel reduced the induction of apoptotic proteins indicating that Pomegranate Peel decreases apoptosis in hepatocytes. The author added that Caspase- 3 is the main critical mediator of apoptosis in most cell types, including hepatocytes.

\section{Conclusion}

In our study, we have shown that Pomegranate Peel extract cotreatment with $\mathrm{CCl}_{4}$ has a potent protective effect against liver damage induced by $\mathrm{CCl}_{4}$ in mice, as revealed by remarkable decrease in hepatic enzymes, serum AST and ALT levels in addition to improvement of many histopathological changes. It also decreases apoptosis by decreasing anti caspas-3 level and decreases fibrosis by decreasing collagen accumulation in the hepatic tissues.

\section{REFERENCES}

[1] Sahu SC. Hepatotoxicity: From Genomics to in vitro and in vivo Models: John Wiley \& Sons; 2008.

[2] Kim H-Y, Kim J-K, Choi J-H, Jung J-Y, Oh W-Y, Kim DC, et al. Hepatoprotective effect of pinoresinol on carbon tetrachloride-induced hepatic damage in mice. Journal of pharmacological sciences. 2010;112:105-12.

[3] Morisco F, Vitaglione P, Amoruso D, Russo B, Fogliano V, Caporaso N. Foods and liver health. Molecular aspects of medicine. 2008;29:144-50.

[4] Prashanth D, Asha M, Amit A. Antibacterial activity of Punica granatum. Fitoterapia. 2001;72:171-3.

[5] Dutta B, Rahman I, Das T. Antifungal activity of Indian plant extracts: Antimyzetische Aktivität indischer Pflanzenextrakte. Mycoses. 1998;41:535-6.

[6] Gharzouli K, Khennouf S, Amira S, Gharzouli A. Effects of aqueous extracts from Quercus ilex L. root bark, Punica granatum L. fruit peel and Artemisia herba-alba Asso leaves on ethanolinduced gastric damage in rats. Phytotherapy Research. 1999;13:42-5.

[7] Lansky EP, Newman RA. Punica granatum (pomegranate) and its potential for prevention and treatment of inflammation and cancer. Journal of ethnopharmacology. 2007;109:177-206.

[8] Singh R, Chidambara Murthy K, Jayaprakasha G. Studies on the antioxidant activity of pomegranate (Punica granatum) peel and seed extracts using in vitro models. Journal of agricultural and food chemistry. 2002;50:81-6.

[9] Gómez-Caravaca AM, Verardo V, Toselli M, Segura-Carretero A, Fernández-Gutiérrez A, Caboni MF. Determination of the major phenolic compounds in pomegranate juices by HPLCDAD-ESI-MS. Journal of agricultural and food chemistry. 2013;61:5328-37.

[10] Ibrahium M. Efficiency of pomegranate peel extract as antimicrobial, antioxidant and protective agents. World Journal of Agricultural Sciences. 2010;6:338-44.

[11] Chidambara Murthy K, Reddy VK, Veigas JM, Murthy UD. Study on wound healing activity of Punica granatum peel. Journal of Medicinal Food. 2004;7:256-9.

[12] Jeune ML, Kumi-Diaka J, Brown J. Anticancer activities of pomegranate extracts and genistein in human breast cancer cells. Journal of medicinal food. 2005;8:469-75.

[13] Tzulker R, Glazer I, Bar-Ilan I, Holland D, Aviram M, Amir R. Antioxidant activity, polyphenol content, and related compounds in different fruit juices and homogenates prepared from 29 different pomegranate accessions. Journal of Agricultural and Food Chemistry. 2007;55:955970. 
[14] Toklu HZ, Sehirli O, Sener G, Dumlu MU, Ercan F, Gedik N, et al. Pomegranate peel extract prevents liver fibrosis in biliary- obstructed rats. Journal of Pharmacy and Pharmacology. 2007;59:1287-95.

[15] Toklu HZ, Şehİrlİ Ö, Özyurt H, Ekşíğglu-Demİralp E, Çetİnel Ş, Şahİn H, et al. Punica granatum peel extract protects against ionizing radiation-induced enteritis and leukocyte apoptosis in rats. Journal of radiation research. 2009;50:345-53.

[16] Xu KZ-Y, Zhu C, Kim MS, Yamahara J, Li Y. Pomegranate flower ameliorates fatty liver in an animal model of type 2 diabetes and obesity. Journal of ethnopharmacology. 2009;123:280-7.

[17] El-Rashedy AH, Belal SK, Osman H, Shehab GM. Protective role of pomegranate on fatty liver in obesity: an experimental chemical \& histopathological study. The Egyptian Journal of Hospital Medicine. 2011;43:162-72.

[18] Osman M, Ahmed M, Mahfouz S, Elaby S. Biochemical studies on the hepatoprotective effects of pomegranate and guava ethanol extracts. New York science journal. 2011;4:27-41.

[19] Sadia H, Akter QS, Afroz R, Siddika T. Effect of Punica Granatum (Pomegranate) on serum ALT and AST in Carbon tetrachloride induced liver damage in Wistar Albino Rats. Journal of Bangladesh Society of Physiologist. 2016;11:23-8.

[20] Wei X-1, Fang R-t, Yang Y-h, Bi X-y, Ren G-x, Luo A-l, et al. Protective effects of extracts from Pomegranate peels and seeds on liver fibrosis induced by carbon tetrachloride in rats. BMC complementary and alternative medicine. 2015;15:1.

[21] Chidambara Murthy KN, Jayaprakasha GK, Singh RP. Studies on antioxidant activity of pomegranate (Punica granatum) peel extract using in vivo models. Journal of Agricultural and Food Chemistry. 2002;50:4791-5.

[22] Kamali M, Tavakoli H, Khodadoost M, Daghaghzadeh H, Kamalinejad M, Gachkar L, et al. Efficacy of the Punica granatum peels aqueous extract for symptom management in ulcerative colitis patients. A randomized, placebo-controlled, clinical trial. Complementary therapies in clinical practice. 2015;21:141-6.

[23] Ghasemi M, Azarnia M, Jamali M, Mirabolghasemi G, Nazarian S, Naghizadeh MM, et al. Protective effects of Ephedra pachyclada extract on mouse models of carbon tetrachlorideinduced chronic and acute liver failure. Tissue and Cell. 2014;46:78-85.

[24] Bancroft J. Gamble. M Theory and Practicle of histological Techniques, 6th ed Churkhil Livinstone, London, UK. 2008:P433-69.

[25] Avwioro G. Histochemical uses of haematoxylin — a review. JPCS. 2011;1:24-34.

[26] Abdel-Wahab BA, Metwally ME. Clozapine-Induced Cardiotoxicity: Role of Oxidative Stress, Tumour Necrosis Factor Alpha and NF- $\kappa \beta$. Cardiovascular toxicology. 2015;15:355-65.

[27] Weber LW, Boll M, Stampfl A. Hepatotoxicity and mechanism of action of haloalkanes: carbon tetrachloride as a toxicological model. Critical reviews in toxicology. 2003;33:105-36.

[28] Singh N, Rajini P. Antioxidant-mediated protective effect of potato peel extract in erythrocytes against oxidative damage. Chemico-Biological Interactions. 2008;173:97-104.

[29] Bilgin HM, Atmaca M, Obay BD, Özekinci S, Taşdemir E, Ketani A. Protective effects of coumarin and coumarin derivatives against carbon tetrachloride-induced acute hepatotoxicity in rats. Experimental and toxicologic pathology. 2011;63:325-30.

[30] Mantawy EM, Tadros MG, Awad AS, Hassan DA, El-Demerdash E. Insights antifibrotic mechanism of methyl palmitate: impact on nuclear factor kappa B and proinflammatory cytokines. Toxicology and applied pharmacology. 2012;258:134-44.

[31] Bashandy S, AlWasel S. Carbon tetrachloride-induced hepatotoxicity and nephrotoxicity in rats: Protective role of vitamin C. Journal of pharmacology and Toxicology. 2011;6:283-92.

[32] Khan RA, Khan MR, Sahreen S, Bokhari J. Prevention of CCl 4-induced nephrotoxicity with Sonchus asper in rat. Food and Chemical Toxicology. 2010;48:2469-76.

[33] Abdel-Rahman MK, El-Megeid AAA. Hepatoprotective effect of soapworts (Saponaria officinalis), pomegranate peel (Punica granatum L) and cloves (Syzygium aromaticum linn) on mice with CCl hepatic intoxication. World Journal of Chemistry. 2006;1:41-6. 
[34] Gil MI, Tomás-Barberán FA, Hess-Pierce B, Holcroft DM, Kader AA. Antioxidant activity of pomegranate juice and its relationship with phenolic composition and processing. Journal of Agricultural and Food chemistry. 2000;48:4581-9.

[35] Sadeghipour A, Eidi M, Ilchizadeh Kavgani A, Ghahramani R, Shahabzadeh S, Anissian A. Lipid lowering effect of Punica granatum L. peel in high lipid diet fed male rats. Evidence-Based Complementary and Alternative Medicine. 2014;2014.

[36] Hamad EM, Taha SH, Dawood A-GIA, Sitohy MZ, Abdel-Hamid M. Protective effect of whey proteins against nonalcoholic fatty liver in rats. Lipids in health and disease. 2011;10:1.

[37] Chung SJ, Lee CH, Lee HS, Kim ST, Sohn UD, Park ES, et al. The role of phosphatidylcholine and deoxycholic acid in inflammation. Life Sciences. 2014;108:88-93.

[38] Na J-Y, Song K, Kim S, Kwon J. Hepatoprotective effect of phosphatidylcholine against carbon tetrachloride liver damage in mice. Biochemical and biophysical research communications. 2015;460:308-13.

[39] Ghiassi-Nejad Z, Friedman SL. Advances in antifibrotic therapy. Expert review of gastroenterology \& hepatology. 2008;2:803-16.

[40] Salwe KJ, Sachdev DO, Bahurupi Y, Kumarappan M. Evaluation of antidiabetic, hypolipedimic and antioxidant activity of hydroalcoholic extract of leaves and fruit peel of Punica granatum in male Wistar albino rats. Journal of natural science, biology, and medicine. 2015;6:56.

[41] Poli G. Pathogenesis of liver fibrosis: role of oxidative stress. Molecular aspects of medicine. 2000;21:49-98.

[42] Wasser S, Ho JMS, Ang HK, Tan CEL. Salvia miltiorrhiza reduces experimentally-induced hepatic fibrosis in rats. Journal of hepatology. 1998;29:760-71.

[43] Cohen GM. Caspases: the executioners of apoptosis. Biochemical Journal. 1997;326:1-16.

[44] Kovalovich K, Li W, DeAngelis R, Greenbaum LE, Ciliberto G, Taub R. Interleukin-6 protects against Fas-mediated death by establishing a critical level of anti-apoptotic hepatic proteins FLIP, Bcl-2, and Bcl-xL. Journal of Biological Chemistry. 2001;276:26605-13.

[45] Dorsey WC, Tchounwou PB, Ford BD. Neuregulin 1-Beta Cytoprotective Role in AML 12 Mouse Hepatocytes Exposed to Pentachlorophenol. International journal of environmental research and public health. 2006;3:11-22.

[46] Jiang W, Gao M, Sun S, Bi A, Xin Y, Han X, et al. Protective effect of L-theanine on carbon tetrachloride-induced acute liver injury in mice. Biochemical and biophysical research communications. 2012;422:344-50. 